\title{
Brain metastasis and treatment
}

\section{Manmeet S. Ahluwalia ${ }^{1}$, Michael A. Vogelbaum ${ }^{1}$, Samuel T. Chao $^{1}$ and Minesh M. Mehta*2}

\author{
Addresses: ${ }^{1}$ Burkhardt Brain Tumor Neuro-Oncology Center, Neurological Institute, Cleveland Clinic, 9500 Euclid Avenue, Cleveland, OH, USA \\ ${ }^{2}$ Department of Radiation Oncology, University of Maryland School of Medicine, Baltimore, MD 21201, USA \\ * Corresponding author: Minesh M. Mehta (mmehta@umm.edu) \\ Fl000Prime Reports 2014, 6:114 (doi:10.12703/P6-I I4) \\ All FI000Prime Reports articles are distributed under the terms of the Creative Commons Attribution-Non Commercial License \\ (http://creativecommons.org/licenses/by-nc/3.0/legalcode), which permits non-commercial use, distribution, and reproduction in any medium, \\ provided the original work is properly cited. \\ The electronic version of this article is the complete one and can be found at: http://fl $000 . c o m / p r i m e / r e p o r t s / m / 6 / I 14$
}

\begin{abstract}
Despite major therapeutic advances in the management of patients with systemic malignancies, management of brain metastases remains a significant challenge. These patients often require multidisciplinary care that includes surgical resection, radiation therapy, chemotherapy, and targeted therapies. Complex decisions about the sequencing of therapies to control extracranial and intracranial disease require input from neurosurgeons, radiation oncologists, and medical/neuro-oncologists. With advances in understanding of the biology of brain metastases, molecularly defined disease subsets and the advent of targeted therapy as well as immunotherapeutic agents offer promise. Future care of these patients will entail tailoring treatment based on host (performance status and age) and tumor (molecular cytogenetic characteristics, number of metastases, and extracranial disease status) factors. Considerable work involving preclinical models and better clinical trial designs that focus not only on effective control of tumor but also on quality of life and neurocognition needs to be done to improve the outcome of these patients.
\end{abstract}

\section{Introduction}

Brain metastases are the most common and devastating neurologic complications of systemic cancer and occur in $10 \%$ to $30 \%$ of adults with cancer [1]. The incidence of brain metastases is increasing because of better detection from improved imaging techniques, more frequent utilization of brain magnetic resonance imaging (MRI) for staging asymptomatic patients, and more effective systemic treatment regimens that can prolong life, permitting the cancer to disseminate to the brain, a sanctuary site [2]. Common systemic malignancies that result in brain metastases include lung, breast, unknown primary, melanoma, and renal cell carcinoma [2]. Most brain metastases are supratentorial in location (80\%), and the cerebellum and brain stem account for $15 \%$ and $5 \%$, respectively [3]. In the past, survival of patients with brain metastases was dismal, there was considerable nihilism in management recommendations, and patients were treated with palliative intent only, typically consisting of whole-brain radiotherapy (WBRT) alone.
More definitive treatments, including surgery and stereotactic radiosurgery (SRS), were used only sporadically or for palliative effect, particularly for histologies that are resistant to fractionated radiotherapy [4-7]. This nihilistic approach to the management of patients with brain metastases changed following the publication of multiple prospective randomized studies, which demonstrated a survival benefit with surgery or SRS as adjuncts to WBRT $[8,9]$. New biological insights and the development of novel cytotoxic agents and targeted therapies that have better blood-brain barrier (BBB) penetration have elevated the interest in systemic therapies for this clinical challenge. In particular, in human epidermal growth factor receptor 2-positive (HER2 ${ }^{+}$) breast cancer, epidermal growth factor receptor (EGFR)-mutated as well as anaplastic lymphoma kinase (ALK)-translocated nonsmall cell lung cancer (NSCLC), and some melanomas, and integration of targeted agents and immune checkpoint inhibitors in the management of brain metastases are gaining considerable traction. 


\section{Graded prognostic index}

The recursive partitioning analysis (RPA), derived from older Radiation Therapy Oncology Group (RTOG) clinical trials, divided patients into three prognostic categories based on Karnofsky performance status (KPS), age, and primary tumor control [10]. The patients in group I had better outcomes than patients in group III (overall survival (OS) 7.1 versus 2.3 months). A more recent diagnosisspecific graded prognostic assessment (DS-GPA) is based on an analysis of approximately 4000 patients with newly diagnosed brain metastases treated between 1985 and 2007 [11]. Multivariate analysis of patients in this database led to the establishment of separate criteria for patients with lung cancer, breast cancer, melanoma, renal cell carcinoma, and gastrointestinal cancer. Further research to elucidate the subtypes of each cancer (for example, NSCLC and breast cancer) has been reported $[12,13]$. In breast cancer, the tumor subtype based on HER2/estrogen receptor/progesterone receptor status is prognostic for OS [12], and the DS-GPA model is being used to stratify patients in an ongoing RTOG study (NCT01622868). In a cohort of patients with NSCLC, EGFR mutation and EML4-ALK translocation were shown to represent radiosensitive genotypes, whereas those harboring KRAS mutations had poor local control [13].

\section{Resection of brain metastases}

Multiple potential benefits are associated with the use of surgery for brain metastases. Surgical removal of a brain metastasis can lead to immediate elimination of lifethreatening or symptom-generating mass effect and elimination of the source of perifocal edema. Surgery has the added benefit of reducing the requirement for and duration of steroid therapy [14]. Surgery is also of value when the diagnosis is unknown or unclear. This is particularly the case when a patient has no known primary tumor or has a primary cancer histology that is unlikely to metastasize to the brain (for example, prostate carcinoma) or a brain lesion that appears several years after the initial primary tumor [15]. It should be kept in mind that, even in patients with a known primary cancer, a newly diagnosed brain mass can turn out to be a primary brain tumor or other non-metastatic disease in about $9 \%$ of cases [9].

Surgery can also provide a survival benefit, as evidenced by two prospective phase III studies. Patchell and colleagues [9] prospectively randomly assigned 48 patients with a single brain metastasis to surgical resection followed by WBRT or WBRT only. The median survival of patients in the surgical group followed by WBRT was significantly prolonged compared with that of the radiotherapy-only group (40 versus 15 weeks, $P<0.01$ ), as was length of functional independence ( 38 versus 8 weeks, $P<0.005$ )
[9]. Similarly, Vecht and colleagues [16] randomly assigned 63 patients to surgery and WBRT versus WBRT only and observed a significant prolongation in survival (10 versus 6 months, $P=0.04$ ) and a trend toward improved maintenance of functional independence [16]. One negative study randomly assigned 84 patients to surgery and WBRT versus WBRT and found no significant difference in survival (5.6 versus 6.3 months, $P=0.24$ ) or maintenance of functional independence [17]. It should be noted, however, that $73 \%$ of patients in this study had poorly controlled extracranial disease, there was unequal distribution of primary pathologies between the groups, and non-uniform calculation of survival times.

The evidence supporting the use of resection for the treatment of multiple brain metastases is less robust, and no prospective randomized studies have addressed this question. Older uncontrolled retrospective studies suggested that patients with multiple brain metastases did not benefit from surgery, compared with the historical results with WBRT alone $[18,19]$. A more recent retrospective study found that patients who underwent removal of all metastases (mostly patients with two lesions) had a significantly longer survival than those in whom at least one lesion was not resected (14 versus 6 months) [4].

Surgical technique has also been the subject of retrospective, but not prospective, evaluation. Some surgeons have advocated the use of "en bloc" techniques, rather than piecemeal resection, in order to reduce the risk of tumor recurrence and leptomeningeal tumor spread [19-21]. This may be a particularly important concern for posterior fossa tumors, in which the risk of leptomeningeal spread appears to be higher than for supratentorial tumors [20,21]. Not all tumors may be resectable in an en bloc manner, however, because of their size, location, and physical characteristics (for example, tumors with a poorly formed capsule).

\section{Whole-brain radiation therapy}

One of the first descriptions of WBRT is from Chao and colleagues [22], who showed that 24 out of 38 patients achieved palliation but that half of these patients recurred by 3.5 months. Borgelt and colleagues [23] reviewed dosing by using the results of two RTOG trials, showing equivalency between various dose fractionation schemes. Currently, $30 \mathrm{~Gy}$ in 10 fractions or $37.5 \mathrm{~Gy}$ in 15 fractions is considered a "standard" dose for WBRT.

After the 1990 study by Patchell and colleagues, the next logical question was whether WBRT is necessary after resection. A randomized study showed that the addition of WBRT, after complete tumor resection, decreased intracranial failure from $70 \%$ to $18 \%(P<0.001)$ and 
decreased local recurrence from $46 \%$ to $10 \%(P<0.001)$ [24]. Although there was improved survival with the use of WBRT, this was not statistically significant, and this study was not powered for assessing a survival benefit. WBRT is therefore typically recommended as adjuvant therapy following surgery.

Typical side effects from WBRT include hair loss, fatigue, headache, skin erythema, and serous otitis media. Somnolence syndrome is rare but may be seen. Long-term side effects include memory loss and leukoencephalopathy. Although neurocognitive dysfunction is typically mild to moderate in most people, this remains the most distressing side effect of WBRT. The RTOG conducted two studies to try to mitigate the neurocognitive effect of WBRT. RTOG 0614 randomly assigned patients to receive memantine, an $\mathrm{N}$-methyl-D-aspartate (NMDA) receptor-agonist, versus placebo [25]. The memantine arm had significantly longer time to cognitive decline $(P=0.02)$. Median declines on Hopkins Verbal Learning Test-Revised (HVLT-R) were 0 in the memantine arm and -2 in the placebo arm at 24 weeks $(P=0.059)$. Also, fewer patients had a decline in Controlled Oral Word Association (COWA) at 16 weeks $(P=0.004)$ or Trail Making Test Part A at 24 weeks $(P=0.014)$. Memantine is started at a low dose and increased to $10 \mathrm{mg}$ twice daily over the course of a few weeks. Patients continue on memantine for 6 months. In general, since patients have to take the drug for 6 months and the benefits of this treatment are best seen afterwards, memantine is best given when life expectancy is 6 months or more.

Hippocampal neural stem cell injury from irradiation during WBRT may play a role in memory decline. Intensitymodulated radiotherapy can be used to conformally avoid the hippocampal neural stem cell compartment during WBRT (hippocampal avoidance [HA]-WBRT). RTOG 0933 was a single-arm phase II study of HA-WBRT for brain metastases with pre-specified comparison with a historical control of patients treated with WBRT without hippocampal avoidance. The primary endpoint was the Hopkins Verbal Learning Test-Revised Delayed Recall (HVLT-R DR) at 4 months. The historical control demonstrated a $30 \%$ mean relative loss in HVLT-R DR from baseline to 4 months. To detect a mean relative loss of not more than $15 \%$ in HVLT-R DR following HA-WBRT, 51 analyzable patients were required to ensure $80 \%$ statistical power with an alpha of 0.05. Quality of life (QOL) assessments included the Functional Assessment of Cancer Therapy and Barthel Activities of Daily Living. Mean relative decline in HVLT-R DR from baseline to 4 months was $7.0 \%$ (95\% confidence interval $[\mathrm{CI}]-4.7 \%$ to $+18.7 \%$ ), which was significantly lower in comparison with the historical control $(P=0.0003)$. No decline in QOL scores up to 6 months was observed [26].

\section{Stereotactic radiosurgery}

SRS involves the delivery of a high dose of radiation focally to the tumor, usually in a single fraction. SRS may be based on a linear particle accelerator or performed with fixed radiation sources, such as Gamma Knife ${ }^{\mathrm{Tm}}$ (Elekta, Stockholm, Sweden). SRS is largely non-invasive, does not require general anesthesia, and is performed on an outpatient basis. It has now become the most widely used focal treatment modality for patients with brain metastasis. RTOG 9005 prospectively identified appropriate and safe doses of SRS, based on lesion size. This study showed that prescription doses of 15, 18, and 24 Gy to the tumor margin were the maximal safe doses for lesions with diameters of 31 to 40,21 to 30 , and $20 \mathrm{~mm}$ or less, respectively [27]. Controversies remain about selecting the exact SRS dose for various disease entities and lesion sizes [28,29].

The efficacy of SRS for brain metastases was first reported in multiple retrospective studies. A large retrospective multiinstitutional analysis of 502 patients stratified by RPA class (I, II, and III) by Sanghavi and colleagues [30] showed that patients receiving WBRT and SRS compared with WBRT alone had significantly increased median survival times of 16.1 versus 7.1 months, 10.3 versus 4.3 months, and 8.7 versus 2.1 months, respectively $(P<0.05)$. A randomized controlled phase III trial (RTOG 9508) of WBRT + SRS versus WBRT alone enrolled 333 patients with one to three brain metastases and a KPS of 70 or greater [31]. Patients with a single lesion had a decreased rate of local recurrence at 1 year ( $18 \%$ versus $29 \%, P=0.01)$ and superior median survival (6.5 versus 4.9 months, $P=0.039$ ) when they received both WBRT and SRS compared with only WBRT. For patients with multiple (two or three) metastases, survival was not significantly improved but local control was. SRS and WBRT also resulted in better outcomes compared with WBRT alone in terms of maintenance or improvement of KPS and steroid use. A smaller prospective study by Kondziolka and colleagues [32] compared WBRT alone versus WBRT plus SRS. This randomized trial was terminated early and enrolled only 27 patients with two to four metastases. Local control rates were $0 \%$ and $92 \%$ for the WBRT only group and the WBRT plus SRS group, respectively. Though not statistically significant, the WBRT plus SRS group had an increased median survival time of 11.0 compared with 7.5 months for WBRT only.

The role of SRS alone, without WBRT, was investigated in subsequent trials. A large retrospective multiinstitutional analysis of 569 patients (268 receiving SRS alone and 301 receiving SRS plus WBRT) showed similar median survivals when stratified by RPA class [33]. Pirzkall and colleagues [34] found that there was no 
significant difference in median survival between SRS alone and SRS plus WBRT in a retrospective analysis of 236 patients, with the exception of one subset of patients. A single-arm, prospective phase II Eastern Cooperative Group trial for patients with "radioresistant" metastases (renal cell, melanoma, and sarcoma) demonstrated a 6-month local and overall intracranial failure rate of $32 \%$, which was considered to be better than the reported tumor control rates for WBRT for these histologies [35]. A randomized trial evaluating the use of SRS with or without WBRT showed no survival difference (8.0 months for SRS versus 7.5 months for SRS plus WBRT; $P=0.42$ ); however, the trial was not powered to detect a significant difference in OS [8].

A prospective randomized Japanese study demonstrated that local control rates were improved with the addition of WBRT to SRS, and 1-year failure rates were $23.6 \%$ for SRS and WBRT and $53.2 \%$ for SRS only $(P<0.001)$. In addition, mini-mental status exam (MMSE) was stable for approximately 2 years after SRS and WBRT compared with SRS alone [36]. The improved local control coupled with stabilization of MMSE suggests the beneficial effect of WBRT on decreasing brain tumor recurrence. Chang and colleagues [37] performed a phase III study for patients with one to three lesions comparing SRS plus WBRT versus SRS alone with the primary endpoint of neurocognitive function measured by the HVLT-R. After accrual of 58 patients, the trial was stopped early based on a high probability that the patients receiving SRS and WBRT would show a statistically significant decline in learning and memory function (total recall) at 4 months. In that study (as in the Japanese study), there were more central nervous system (CNS) recurrences in the group receiving SRS alone; $73 \%$ of patients in the SRS and WBRT group were free from CNS recurrence at 1 year, compared with $27 \%$ of patients who received SRS alone $(P=0.0003)$.

The North Central Cancer Treatment Group (NCCTG) has recently completed accrual to a phase III trial (N0574) comparing SRS versus SRS followed by WBRT delivered within 14 days for patients with one to three brain metastases. Results are pending. According to emerging data presented by Sahgal and colleagues [38], for patients 50 years or younger with one to four brain metastases, there is an OS advantage to SRS alone based on a meta-analysis of three phase III studies (10 versus 8.2 months).

SRS has also been used as salvage therapy in progressive disease following WBRT. A 111-patient retrospective study from the Cleveland Clinic demonstrated a local control rate of $73 \%$ with SRS, with a median follow-up of 15.4 months [39]. Although SRS is typically offered for patients with four or fewer brain metastases, SRS is increasingly being used for patients with five or more brain metastases. A retrospective review from the Cleveland Clinic found that the median OS after SRS for five or more brain metastases was 7.5 months [40]. KPS of 80 or more was a significant predictor for survival. Interestingly, the number of brain metastases was not a significant predictor of survival, but this may have been due to the relatively small size of the study. Higher intracranial burden (higher volume of brain metastases within the brain) predicted poorer outcomes [41]. The Japanese Leksell Gamma Knife Society conducted a study for one to 10 brain metastases and showed no difference in OS whether patients had two to four versus five or more brain metastases when treated with SRS alone [42]. This suggests that SRS alone may be a reasonable approach in selected patients with up to 10 brain metastases.

Another active area of investigation is the use of SRS to prevent local recurrence after resection in lieu of WBRT. Rather than targeting an enhancing tumor, resection bed SRS can be made more complex because of uncertainties regarding the interpretation of a postoperative MRI. Soltys and colleagues [43] reported 1-year local control rates of $94 \%$ when a $2 \mathrm{~mm}$ margin was added around the defined tumor bed and $78 \%$ when no margin was added. Median OS was 17 months, and $72 \%$ of patients were able to avoid WBRT. One concern regarding surgical bed SRS is the possibility of leptomeningeal spread secondary to the resection, especially for patients with breast cancer and those with posterior fossa disease [44]. The NCCTG, in collaboration with RTOG, is conducting a study randomly assigning patients to WBRT versus resection bed SRS.

One novel approach to potentially minimizing leptomeningeal spread is to perform SRS prior to resection, which would "sterilize" the tumor cells prior to the resection. Neoadjuvant SRS was reported by Asher and colleagues [45]. This study involved 47 patients, 24 of whom were treated prospectively. These patients underwent SRS to a median dose of $14 \mathrm{~Gy}$ (range of 11.8 to 18). Surgery was performed a median of 1 day after SRS. Local control was good at $85.6 \%$ at 1 year, and only $14.8 \%$ of the patients eventually required WBRT. There were no leptomeningeal failures. Given these results, the Cleveland Clinic is conducting a dose escalation study with neoadjuvant SRS for lesions that are 2 to $5 \mathrm{~cm}$ in diameter.

Whether SRS can replace surgery remains unanswered in terms of level 1 evidence. An international randomized phase III trial compared surgery or radiosurgery with or without adjuvant WBRT and noted that the addition of WBRT to either surgery or radiosurgery did not alter 
survival but did improve CNS control and reduced the risk of death due to intracranial progression [46]. This study, however, did not specifically compare surgery with radiosurgery. More than one randomized effort to answer this question has failed because of poor accrual and preconceived bias. Therefore, only retrospective studies are available to address this issue. Bindal and colleagues [7] reported on a retrospectively matched series of 75 patients treated by surgery and SRS. The median survival rates were 7.5 months with SRS and 16.4 months in the surgical group. There is concern, however, that the dosing regimen used in the radiosurgery group resulted in the use of lower prescriptions to the tumor margin than would be considered standard according to the widely accepted RTOG dosing schema [27,31]. Auchter and colleagues [47] retrospectively analyzed a multiinstitutional dataset of SRS in 122 highly selected patients with a resectable single brain metastasis. The median survival was 56 weeks, comparable to the results of most surgical series. A retrospective study from Muacevic and colleagues [48] compared surgery and radiotherapy with radiosurgery for patients with a single tumor $3.5 \mathrm{~cm}$ or less in diameter. The 1-year survival rates (53\% versus $43 \%, P=0.19$ ), 1 -year local control rates (75\% versus $83 \%, P=0.49$ ), and 1 -year neurologic death rates (37\% versus $39 \%, P=0.8)$ for the surgical group and SRS group, respectively, were not statistically different. Schoggl and colleagues [49] treated 133 patients with either radiosurgery (SRS, $n=67)$ or surgery $(n=66)$, along with WBRT, and performed a retrospective casecontrol analysis of their results. These investigators found no difference in median survival (SRS versus surgery, 12 versus 9 months, $P=0.19$ ) but did find a superior local control rate with SRS $(P<0.05)$, likely attributable to the improved outcome of patients with histologies resistant to WBRT. O'Neill and colleagues [50] retrospectively compared surgery and SRS for treatment of solitary brain metastasis and found no significant difference in patient survival. The difference in local tumor control rate, however, was significantly different (100\% following SRS and 58\% after surgery).

\section{Systemic therapy}

The role of systemic therapy, chemotherapy, or targeted therapy or immunotherapy in the management of patients with brain metastases is not well defined. There is no level 1 evidence favoring the use of systemic therapy compared with local therapies in brain metastases. At present, no standard cytotoxic chemotherapy is routinely used for the treatment of brain metastases. In patients with brain metastases that have failed local therapy with surgery or radiation, the same chemotherapeutic agents employed for the treatment of extracranial disease are often used. Alternatively, drugs with good CNS penetration, such as temozolomide, topotecan, and irinotecan, may be employed, even in patients in whom the chemotherapy might have, at most, minor efficacy against the primary tumor. Improved understanding of tumor biology has led to the identification of specific molecular drivers of cancer development and progression. Alterations involving the EGFR gene and EML4-ALK chromosomal translocation in lung cancer, HER2 protein overexpression in breast cancer, and BRAF mutation in melanoma are examples of distinct subsets of cancer amenable to unique treatment approaches. A number of prospective studies in the last 3 to 5 years have particularly focused on targeted therapy or immunotherapy.

\section{Inhibitors targeting EGFR in non-small cell lung cancer}

The combination of targeted therapy or chemotherapy with WBRT has the premise of these agents serving as a potential radiation sensitizer to increase the efficacy of the radiation. However, the RTOG 0320 trial did not show any additional benefit of temozolomide or erlotinib when added to WBRT and SRS in patients with NSCLC with one to three brain metastases [51]. In fact, the patients in the control arm of SRS and WBRT had the best outcomes; progression-free survival (PFS) and OS were 8.1 and 13.4 months for WBRT and SRS compared with 4.6 and 6.3 months for WBRT, SRS, and temozolomide and 4.8 and 6.1 for WBRT, SRS, and erlotinib [51]. However, one of the limitations of the study was that patients were not stratified according to EGFR mutational status. In a phase II study of 40 NSCLC patients with brain metastases, the combination of WBRT and erlotinib was safe (no reported increase in neurotoxicity) and the median survival time was 11.8 months [52]. In the 17 patients with known EGFR status, the benefit of erlotinib was more pronounced in the mutant EGFR patients (OS of 19.1 months) as compared with the wild-type EGFR patients (OS of 9.3 months) [52]. In a large cohort of 110 patients with EGFR mutant lung cancer with newly diagnosed brain metastases, patients treated with WBRT (32 patients) had longer median time to intracranial progression compared with 63 patients who received erlotinib therapy upfront (24 versus 16 months) [53]. Patients treated with erlotinib or SRS experienced intracranial failure as a component of first failure more commonly, whereas WBRT patients experienced failure outside the brain more often. The OS was similar between the WBRT and erlotinib groups, and patients treated with SRS initially had a longer OS compared with those who received erlotinib.

In a prospective phase II study of gefitinib in 41 NSCLC patients unselected for EGFR mutation, an objective response rate of $10 \%$ in the brain was seen [54]. Higher response rates were reported in studies of EGFR inhibitors 
in enriched with patients with known EGFR mutations [55,56]. In a phase II study of 28 patients with EGFR mutant NSCLC with brain metastases, a partial response rate of $83 \%$ and a disease control rate of $93 \%$ were seen with treatment with erlotinib or gefitinib [55].

\section{Inhibitors targeting HER2 in breast cancer}

Several prospective clinical trials have evaluated the role of lapatinib-based therapy in HER2 ${ }^{+}$breast cancer patients with active brain metastases [57-60]. In a large phase II study of lapatinib in 242 patients with HER2 ${ }^{+}$ breast cancer and progressive brain metastases after WBRT or SRS (or both), a CNS response rate of $6 \%$ was seen [58]. Fifty patients who progressed were treated with a combination of lapatinib and capecitabine, and 20\% achieved a CNS objective response. In the Lapatinib Plus Capecitabine in Patients With Previously Untreated Brain Metastases from HER2-positive Metastatic Breast Cancer (LANDSCAPE) study, a single-arm, phase II study, 29 of the 45 patients with newly diagnosed, previously untreated brain metastases from HER2 ${ }^{+}$breast cancer achieved an objective CNS response (66\%), albeit all were partial responses [60]. A randomized phase II study of WBRT with or without lapatinib in patients with HER $2^{+}$breast cancer with brain metastases is ongoing (NCT01622868).

\section{Inhibitors targeting BRAF in melanoma}

Activating BRAF mutations that result in constitutive activation of the mitogen-activated protein kinase pathway affect approximately half of patients with melanoma, and more than $95 \%$ of these are the V600E mutation (substitution of valine by glutamic acid at the 600th amino acid position) [61]. In an open-label phase II study, BRAF-mutant melanoma metastatic to the brain (BREAK-MB), 172 patients with V600E or V600K mutation-positive melanoma metastatic to the brain were treated with dabrafenib [62]. Patients in cohort A had not received any prior local therapy, and cohort B had disease progression in the brain following local therapy (surgery, WBRT, and SRS). Twenty-nine (39\%) of 74 patients with V600E BRAF-mutant melanoma in cohort A and 20 of 65 patients in cohort B achieved an overall intracranial response. This study provided initial evidence that dabrafenib has activity in patients with V600E BRAF-mutant melanoma brain metastases irrespectively of prior local therapy.

In a prospective study, 24 patients with V600E BRAF mutation-positive melanoma brain metastases were treated with vemurafenib. Of 19 patients with measurable intracranial disease, 7 (37\%) achieved at least 30\% intracranial tumor regression, and $3(16 \%)$ achieved a confirmed partial response, whereas $13(62 \%)$ out of
21 patients had extracranial responses [63]. In a retrospective study of 283 patients with V600 BRAF mutationpositive melanoma brain metastases, $136(48.1 \%)$ out of 283 were reported to achieve overall intracranial response (complete response/partial response). OS at 6 months was an impressive $86 \%$. A phase II study of vemurafenib in 146 patients with V600 BRAF mutation-positive melanoma brain metastases (NCT01378975), with or without prior treatment for their brain metastases, has completed accrual.

\section{Immune-modulating approaches}

The development of immune-modulating agents, specifically immune checkpoint inhibitors, offers an exciting opportunity for treating patients with brain metastases. Previously, immunotherapy was thought to be ineffective in patients with brain tumors and brain metastases because it was felt that these agents would not cross an intact BBB and that, even if they did, the ability to mount a robust immune response in the brain would be somewhat limited. However, recent research has demonstrated that activated $\mathrm{T}$ cells can be effective in brain metastases and other intracranial tumors [64]. In a phase II study, 72 melanoma patients with brain metastases were treated with ipilimumab, a monoclonal antibody against cytotoxic T-lymphocyte-associated protein 4 (CTLA-4) [65]. Cohort A consisted of 51 patients who were neurologically asymptomatic and not on corticosteroids, and cohort B included 21 patients who were neurologically symptomatic and on steroids. Twelve $(24 \%)$ of 51 patients in cohort A and two $(10 \%)$ of 21 patients in cohort B achieved CNS disease control (partial response or stable disease). Median OS rates were 7.0 months in cohort A and 3.7 months in cohort B. This study demonstrated that ipilimumab could have some activity in recurrent brain metastases, and further evaluation, especially in a combinatorial manner, is proceeding.

\section{Primary endpoints in trials of brain metastases}

The choice of endpoints in brain metastases trials is challenging because of the need to account for not only intracranial metastases but also extracranial disease. OS is usually the primary endpoint in phase III trials of brain metastases. However, up to $60 \%$ of patients with brain metastases die from extracranial disease progression independently of intracranial disease control [66]. Hence the use of OS as the primary endpoint in brain metastases trials may not be reflective of the activity of the agent or the modality in the brain as majority of patients die of extracranial disease [67]. The use of PFS as the primary endpoint in brain metastases trials in studies of SRS with or without WBRT is limited by its ability to take into account the concerns about neurocognitive decline associated with WBRT. It can be difficult to accurately 
distinguish progression from radiation-related changes, particularly after SRS by routine MRI. In addition, there are challenges related to which criteria to adopt-Response Evaluation Criteria in Solid Tumors (RECIST), World Health Organization (WHO), Macdonald, and Response Assessment in Neuro-Oncology (RANO)-to define response and progression. To circumvent these challenges and to take advantage of the fact that intracranial recurrence can be managed effectively with close surveillance, some of the recent trials have employed neurocognitive outcomes as the primary endpoint and have focused on functional status and QOL as secondary endpoints [37]. The RANO working group is making an active ongoing effort to define the appropriate endpoints to adopt in brain metastases trials (personal communication, Patrick Wen).

\section{Other approaches and future trial directions}

One approach is to consider preventive strategy in patients at high risk for developing brain metastases. A number of drugs can potentially help prevent the overt development of brain metastases (for example, temozolomide, pazopanib, and vorinostat) [68]. Mouse models developed in the laboratory of Steeg and colleagues [68] have suggested that temozolomide could putatively decrease the emergence of brain metastases in breast cancer, and a clinical trial to test this concept is planned by the Southwest Oncology Group (SWOG) (Christina Tsien and colleagues, personal communication). A trial of temozolomide after definitive treatment in locoregionally advanced NSCLC failed to demonstrate any reduction in the development of brain metastases (Robins HI, personal communication). A phase III trial compared lapatinib plus capecitabine versus trastuzumab plus capecitabine with the aim that the former combination of lapatinib and capecitabine would prevent the development of CNS metastases [69]. The study failed to meet its primary endpoint, possibly because it required brain imaging at baseline that resulted in a $20 \%$ rate of screen failure, which likely resulted in a paucity of events, making the study underpowered to address the prevention question. The development of targeted therapy (small-molecule inhibitors) with better BBB penetration and improved molecular and clinical predictors to enrich for patients with a high risk of brain metastases will aid such future studies.

Another approach that has gained traction in the last few years is of secondary prevention, in which patients with limited brain metastases (usually one to four brain metastases) are treated with SRS and then receive a targeted agent (with good BBB penetration) to control both the intracranial micro-metastases and the systemic disease. The aim is to avoid WBRT in patients who have good performance status and prognosis until patients relapse to mitigate or delay the neurocognitive side effects of WBRT. An ongoing phase II study of the combination of dabrafenib with SRS in BRAF V600E melanoma brain metastases uses this strategy (NCT01721603). An institutional trial using lapatanib/capecitabine or trastuzumabemtansine (TDM-1) in HER $2^{+}$breast cancer patients with one to 10 brain metastases treated with radiosurgery is in development (Minesh Mehta and colleagues, personal communication). Furthermore, a recently approved device, NovoTTF, which delivers low-voltage alternating electrical current to the brain and which has been approved for use in recurrent glioblastoma, is being considered under a company-sponsored trial in patients with NSCLC and one to 10 brain metastases treated with SRS (Vinai Gondi and colleagues, personal communication).

Significant interest remains in minimizing the impact of WBRT. Based on the encouraging results with the use of memantine as well as hippocampal sparing, further trials incorporating both strategies are being pursued. Trials avoiding WBRT are also under way; an intergroup trial of SRS with or without WBRT in patients with one to four brain metastases has completed accrual, and a similar industry-supported trial in patients with one to 10 brain metastases is under way.

\section{Summary and Conclusions}

The treatment of patients with brain metastases requires a multidisciplinary team approach in which treatment recommendations (surgery, WBRT, SRS, and systemic therapy) are based on host (performance status and age) and tumor (type and subtype of tumor, number of metastases, and extracranial disease status) factors. An individualized plan to improve the outcome of patients with this life-limiting complication is optimal. Molecularly defined disease subsets and targeted therapies as well as immunotherapeutic agents will aid in improved outcomes in patients with brain metastases. WBRT retains an important place in the management of this disease, but its application and role are being rapidly redefined.

\section{Abbreviations}

$\mathrm{BBB}$, blood-brain barrier; CNS, central nervous system; DS-GPA, diagnosis-specific graded prognostic assessment; EGFR, epidermal growth factor receptor; HA-WBRT, hippocampal avoidance whole-brain radiotherapy; HER2 $^{+}$; human epidermal growth factor receptor 2positive, HVLT-R, Hopkins Verbal Learning Test-Revised; HVLT-R DR, Hopkins Verbal Learning Test-Revised Delayed Recall; KPS, Karnofsky performance status; MMSE, mini-mental status exam; MRI, magnetic resonance imaging; NCCTG, North Central Cancer Treatment 
Group; NSCLC, non-small cell lung cancer; OS, overall survival; PFS, progression-free survival; QOL, quality of life; RANO, Response Assessment in Neuro-Oncology; RPA, recursive partitioning analysis; RTOG, Radiation Therapy Oncology Group; SRS, stereotactic radiosurgery; WBRT, whole-brain radiotherapy.

\section{Disclosures}

Manmeet Ahluwalia has received honorarium from Elekta. Michael Vogelbaum declares that he has no disclosures. Samuel Chao has served on a speakers bureau for Varian. Minesh Mehta has served as a consultant for Abbott, Bristol-Myers Squibb, Elekta, Genentech, Merck, Novocure, and Phillips and is on the board of directors of Pharmacyclics and has stock options.

\section{References}

I. DeAngelis L, Posner J: Intracranial metastases. In Neurologic complications of cancer. Edited by DeAngelis L, Posner J. New York Oxford University Press; 2009: 14I-193.

2. Nayak L, Lee EQ, Wen PY: Epidemiology of brain metastases. Curr Oncol Rep 2012, 14:48-54.

3. Tsao MN, Lloyd N, Wong, Rebecca KS, Chow E, Rakovitch E, Laperriere N, Xu W, Sahgal A: Whole brain radiotherapy for the treatment of newly diagnosed multiple brain metastases. Cochrane Database Syst Rev 2012, 4:CD003869.

4. Bindal RK, Sawaya R, Leavens ME, Lee J]: Surgical treatment of multiple brain metastases. J Neurosurg 1993, 79:210-6.

5. Lang FF, Sawaya R: Surgical treatment of metastatic brain tumors. Semin Surg Oncol 1998, 14:53-63.

6. Lang FF, Sawaya R: Surgical management of cerebral metastases. Neurosurg Clin N Am 1996, 7:459-84.

7. Bindal AK, Bindal RK, Hess KR, Shiu A, Hassenbusch SJ, Shi WM, Sawaya R: Surgery versus radiosurgery in the treatment of brain metastasis. J Neurosurg 1996, 84:748-54.

8. Aoyama H, Shirato H, Tago M, Nakagawa K, Toyoda T, Hatano K, Kenjyo M, Oya N, Hirota S, Shioura H, Kunieda E, Inomata T, Hayakawa K, Katoh N, Kobashi G: Stereotactic radiosurgery plus whole-brain radiation therapy vs stereotactic radiosurgery alone for treatment of brain metastases: a randomized controlled trial. JAMA 2006, 295:2483-91.

\section{FlOOOPrime \\ RECOMMENDED}

9. Patchell RA, Tibbs PA, Walsh JW, Dempsey RJ, Maruyama Y, Kryscio RJ, Markesbery WR, Macdonald JS, Young B: A randomized trial of surgery in the treatment of single metastases to the brain. $N$ Engl J Med 1990, 322:494-500.

\section{FlOOOPrime \\ RECOMMENDED}

10. Gaspar L, Scott C, Rotman M, Asbell S, Phillips T, Wasserman T, McKenna WG, Byhardt R: Recursive partitioning analysis (RPA) of prognostic factors in three Radiation Therapy Oncology Group (RTOG) brain metastases trials. Int J Radiat Oncol Biol Phys |997, 37:745-51.

II. Sperduto PW, Kased N, Roberge D, Xu Z, Shanley R, Luo X, Sneed PK, Chao ST, Weil RJ, Suh J, Bhatt A, Jensen AW, Brown PD, Shih HA, Kirkpatrick J, Gaspar LE, Fiveash JB, Chiang V, Knisely, Jonathan PS, Sperduto CM, Lin N, Mehta M: Summary report on the graded prognostic assessment: an accurate and facile diagnosis-specific tool to estimate survival for patients with brain metastases. J Clin Oncol 2012, 30:419-25.
12. Sperduto PW, Kased N, Roberge D, Xu Z, Shanley R, Luo X, Sneed PK, Chao ST, Weil RJ, Suh J, Bhatt A, Jensen AW, Brown PD, Shih HA, Kirkpatrick J, Gaspar LE, Fiveash JB, Chiang V, Knisely JP, Jonathan PS, Sperduto CM, Lin N, Mehta M: Effect of tumor subtype on survival and the graded prognostic assessment for patients with breast cancer and brain metastases. Int J Radiat Oncol Biol Phys 2012, 82:21 II-7.

13. Johung KL, Yao X, Li F, Yu JB, Gettinger SN, Goldberg S, Decker RH, Hess JA, Chiang VL, Contessa JN: A clinical model for identifying radiosensitive tumor genotypes in non-small cell lung cancer. Clin Cancer Res 2013, 19:5523-32.

\section{FlOOOPrime
RECOMMENDED}

14. Hempen C, Weiss E, Hess CF: Dexamethasone treatment in patients with brain metastases and primary brain tumors: do the benefits outweigh the side-effects? Support Care Cancer 2002, 10:322-8.

I5. Hatzoglou V, Patel GV, Morris MJ, Curtis K, Zhang Z, Shi W, Huse J, Rosenblum M, Holodny Al, Young RJ: Brain metastases from prostate cancer: an II-year analysis in the MRI era with emphasis on imaging characteristics, incidence, and prognosis. J Neuroimaging 2014, 24:161-6.

\section{FIOOOPrime
RECOMMENDED}

16. Vecht CJ, Haaxma-Reiche H, Noordijk EM, Padberg GW, Voormolen JH, Hoekstra FH, Tans JT, Lambooij N, Metsaars JA, Wattendorff AR: Treatment of single brain metastasis: radiotherapy alone or combined with neurosurgery? Ann Neurol 1993, 33:583-90.

\section{FlOOOPrime} RECOMMENDED

17. Mintz AH, Kestle J, Rathbone MP, Gaspar L, Hugenholtz H, Fisher B, Duncan G, Skingley P, Foster G, Levine M: A randomized trial to assess the efficacy of surgery in addition to radiotherapy in patients with a single cerebral metastasis. Cancer 1996, 78: I 470-6.

18. Haar F, Patterson RH: Surgical for metastatic intracranial neoplasm. Cancer 1972, 30:1241-5.

19. Ransohoff J: Surgical management of metastatic tumors. Semin Oncol 1975, 2:21-7.

20. van der Ree, TC, Dippel DW, Avezaat CJ, Sillevis Smitt, PA, Vecht CJ, van den Bent, MJ: Leptomeningeal metastasis after surgical resection of brain metastases. J Neurol Neurosurg Psychiatr 1999, 66:225-7.

21. Siomin VE, Vogelbaum MA, Kanner AA, Lee S, Suh JH, Barnett GH: Posterior fossa metastases: risk of leptomeningeal disease when treated with stereotactic radiosurgery compared to surgery. J Neurooncol 2004, 67: I I5-21.

22. Chao JH, Phillips R, Nickson J]: Roentgen-ray therapy of cerebral metastases. Cancer 1954, 7:682-9.

23. Borgelt B, Gelber R, Larson M, Hendrickson F, Griffin T, Roth R: Ultrarapid high dose irradiation schedules for the palliation of brain metastases: final results of the first two studies by the Radiation Therapy Oncology Group. Int J Radiat Oncol Biol Phys I 98I, 7: I633-8.

24. Patchell RA, Tibbs PA, Regine WF, Dempsey RJ, Mohiuddin M, Kryscio RJ, Markesbery WR, Foon KA, Young B: Postoperative radiotherapy in the treatment of single metastases to the brain: a randomized trial. JAMA 1998, 280: I485-9.

25. Brown PD, Pugh S, Laack NN, Wefel JS, Khuntia D, Meyers C, Choucair A, Fox S, Suh JH, Roberge D, Kavadi V, Bentzen SM, Mehta MP, Watkins-Bruner D: Memantine for the prevention of cognitive dysfunction in patients receiving whole-brain radiotherapy: a randomized, double-blind, placebo-controlled trial. Neuro-oncology 2013, 15:1429-37.

26. Gondi VMMPST WA, Kanner A, Caine C, Rowley H, Kundapur V, Greenspoon, JN, Kachni, Lc: Memory Preservation With Conformal Avoidance of the Hippocampus During Whole-Brain Radiation Therapy for Patients With Brain Metastases: Primary Endpoint Results of RTOG 0933. International Journal Radiation Oncology Biology Physics 2013, 87:। 186. 
27. Shaw E, Scott C, Souhami L, Dinapoli R, Kline R, Loeffler J, Farnan N: Single dose radiosurgical treatment of recurrent previously irradiated primary brain tumors and brain metastases: final report of RTOG protocol 90-05. Int I Radiat Oncol Biol Phys 2000, 47:29I-8.

28. Shehata MK, Young B, Reid B, Patchell RA, St Clair W, Sims J, Sanders M, Meigooni A, Mohiuddin M, Regine WF: Stereotatic radiosurgery of 468 brain metastases or $=2 \mathrm{~cm}$ : implications for SRS dose and whole brain radiation therapy. Int J Radiat Oncol Biol Phys 2004, 59:87-93.

\section{FlOOOPrime} RECOMMENDED

29. Vogelbaum MA, Angelov L, Lee S, Li L, Barnett GH, Suh JH: Local control of brain metastases by stereotactic radiosurgery in relation to dose to the tumor margin. J Neurosurg 2006, I04:907-I2.

30. Sanghavi SN, Miranpuri SS, Chappell R, Buatti JM, Sneed PK, Suh JH, Regine WF, Weltman E, King VJ, Goetsch SJ, Breneman JC, Sperduto PW, Scott C, Mabanta S, Mehta MP: Radiosurgery for patients with brain metastases: a multi-institutional analysis, stratified by the RTOG recursive partitioning analysis method. Int J Radiat Oncol Biol Phys 200I, 5 I:426-34.

31. Andrews DW, Scott CB, Sperduto PW, Flanders AE, Gaspar LE, Schell MC, Werner-Wasik M, Demas W, Ryu J, Bahary J, Souhami L, Rotman M, Mehta MP, Curran W]: Whole brain radiation therapy with or without stereotactic radiosurgery boost for patients with one to three brain metastases: phase III results of the RTOG 9508 randomised trial. Lancet 2004, 363:1665-72.

32. Kondziolka D, Patel A, Lunsford LD, Kassam A, Flickinger JC: Stereotactic radiosurgery plus whole brain radiotherapy versus radiotherapy alone for patients with multiple brain metastases. Int J Radiat Oncol Biol Phys 1999, 45:427-34.

33. Sneed PK, Suh JH, Goetsch SJ, Sanghavi SN, Chappell R, Buatti JM, Regine WF, Weltman E, King VJ, Breneman JC, Sperduto PW, Mehta MP: A multi-institutional review of radiosurgery alone vs. radiosurgery with whole brain radiotherapy as the initial management of brain metastases. Int J Radiat Oncol Biol Phys 2002, 53:519-26.

34. Pirzkall A, Debus J, Lohr F, Fuss M, Rhein B, Engenhart-Cabillic R, Wannenmacher M: Radiosurgery alone or in combination with whole-brain radiotherapy for brain metastases. J Clin Oncol 1998, 16:3563-9.

35. Manon R, O'Neill A, Knisely J, Werner-Wasik M, Lazarus HM, Wagner $\mathrm{H}$, Gilbert M, Mehta M: Phase II trial of radiosurgery for one to three newly diagnosed brain metastases from renal cell carcinoma, melanoma, and sarcoma: an Eastern Cooperative Oncology Group study (E 6397). J Clin Oncol 2005, 23:8870-6.

36. Aoyama H, Tago M, Kato N, Toyoda T, Kenjyo M, Hirota S, Shioura H, Inomata T, Kunieda E, Hayakawa K, Nakagawa K, Kobashi G, Shirato H: Neurocognitive function of patients with brain metastasis who received either whole brain radiotherapy plus stereotactic radiosurgery or radiosurgery alone. Int J Radiat Oncol Biol Phys 2007, 68:1388-95

\section{FlOOOPrime} RECOMMENDED

37. Chang EL, Wefel JS, Hess KR, Allen PK, Lang FF, Kornguth DG, Arbuckle RB, Swint JM, Shiu AS, Maor MH, Meyers CA: Neurocognition in patients with brain metastases treated with radiosurgery or radiosurgery plus whole-brain irradiation: a randomised controlled trial. Lancet Oncol 2009, 10:1037-44.

\section{FlOOOPrime}

\section{RECOMMENDED}

38. Sahgal A, Aoyama H, Kocher M, Neupane B, Collette S, Tago M, Shaw P, Beyene J, Chang EL: Individual patient data (IPD) metaanalysis of radomized controlled trials comparing stereotactic radiosurgery (SRS) alone to SRS plus whole brain radiation therapy in patients with brain metastases. J Rad Onc Biol Phys, 2013 87: I 187.
39. Chao ST, Barnett GH, Vogelbaum MA, Angelov L, Weil RJ, Neyman G, Reuther AM, Suh JH: Salvage stereotactic radiosurgery effectively treats recurrences from whole-brain radiation therapy. Cancer 2008, I I 3:21 98-204.

40. Hunter GK, Suh JH, Reuther AM, Vogelbaum MA, Barnett GH, Angelov L, Weil RJ, Neyman G, Chao ST: Treatment of five or more brain metastases with stereotactic radiosurgery. Int J Radiat Oncol Biol Phys 2012, 83:1394-8.

\section{FlOOOPrime}

RECOMMENDED

4I. Mohammadi AM, Recinos PF, Barnett GH, Weil RJ, Vogelbaum MA Chao ST, Suh JH, Marko NF, Elson P, Neyman G, Angelov L: Role of Gamma Knife surgery in patients with 5 or more brain metastases. J Neurosurg 2012, I I 7(Suppl):5-12.

42. Yamamoto M, Serizawa T, Shuto T, Akabane A, Higuchi Y, Kawagishi J, Yamanaka K, Sato Y, Jokura H, Yomo S, Nagano O, Kenai H, Moriki A, Suzuki S, Kida Y, Iwai Y, Hayashi M, Onishi H, Gondo M, Sato M, Akimitsu T, Kubo K, Kikuchi Y, Shibasaki T, Goto T, Takanashi M, Mori Y, Takakura K, Saeki N, Kunieda E et al.: Stereotactic radiosurgery for patients with multiple brain metastases (JLGK090 I): a multiinstitutional prospective observational study. Lancet Oncol 2014, I 5:387-95.

\section{FlOOOPrime}

\section{RECOMMENDED}

43. Choi, Clara YH, Chang SD, Gibbs IC, Adler JR, Harsh GR, Lieberson RE, Soltys SG: Stereotactic radiosurgery of the postoperative resection cavity for brain metastases: prospective evaluation of target margin on tumor control. Int J Radiat Oncol Biol Phys 20I2, 84:336-42.

\section{FlOOOPrime \\ RECOMMENDED}

44. Atalar B, Modlin LA, Choi, Clara YH, Adler JR, Gibbs IC, Chang SD, Harsh GR, Li G, Nagpal S, Hanlon A, Soltys SG: Risk of leptomeningeal disease in patients treated with stereotactic radiosurgery targeting the postoperative resection cavity for brain metastases. Int J Radiat Oncol Biol Phys 2013, 87:713-8.

\section{FlOOOPrime}

\section{RECOMMENDED}

45. Asher AL, Burri SH, Wiggins WF, Kelly RP, Boltes MO, Mehrlich M, Norton HJ, Fraser RW: A new treatment paradigm: neoadjuvant radiosurgery before surgical resection of brain metastases with analysis of local tumor recurrence. Int J Radiat Oncol Biol Phys 2014, 88:899-906.

\section{FlOOOPrime}

46. Kocher M, Soffietti R, Abacioglu U, Villà $S$, Fauchon F, Baumert BG, Fariselli L, Tzuk-Shina T, Kortmann R, Carrie C, Ben Hassel M, Kouri M, Valeinis E, van den Berge, Dirk, Collette S, Collette L, Mueller R: Adjuvant whole-brain radiotherapy versus observation after radiosurgery or surgical resection of one to three cerebral metastases: results of the EORTC 22952-2600 I study. J Clin Oncol 20II, 29:|34-4I.

\section{FlOOPrime}

\section{RECOMMENDED}

47. Auchter RM, Lamond JP, Alexander E, Buatti JM, Chappell R, Friedman WA, Kinsella TJ, Levin AB, Noyes WR, Schultz C], Loeffler JS, Mehta MP: A multiinstitutional outcome and prognostic factor analysis of radiosurgery for resectable single brain metastasis. Int J Radiat Oncol Biol Phys 1996, 35:27-35.

48. Muacevic A, Kreth FW, Horstmann GA, Schmid-Elsaesser R, Wowra B, Steiger HJ, Reulen HJ: Surgery and radiotherapy compared with gamma knife radiosurgery in the treatment of solitary cerebral metastases of small diameter. J Neurosurg 1999, 91:35-43.

49. Schöggl A, Kitz K, Reddy M, Wolfsberger S, Schneider B, Dieckmann K, Ungersböck K: Defining the role of stereotactic radiosurgery versus microsurgery in the treatment of single brain metastases. Acta Neurochir (Wien) 2000, 142:621-6. 
50. O'Neill BP, Iturria NJ, Link MJ, Pollock BE, Ballman KV, O'Fallon JR: A comparison of surgical resection and stereotactic radiosurgery in the treatment of solitary brain metastases. Int J Radiat Oncol Biol Phys 2003, 55: I 169-76.

5I. Sperduto PW, Wang M, Robins HI, Schell MC, Werner-Wasik M, Komaki R, Souhami L, Buyyounouski MK, Khuntia D, Demas W, Shah SA, Nedzi LA, Perry G, Suh JH, Mehta MP: A phase 3 trial of whole brain radiation therapy and stereotactic radiosurgery alone versus WBRT and SRS with temozolomide or erlotinib for non-small cell lung cancer and I to 3 brain metastases: Radiation Therapy Oncology Group 0320. Int J Radiat Oncol Biol Phys 2013, 85:1312-8.

52. Welsh JW, Komaki R, Amini A, Munsell MF, Unger W, Allen PK, Chang JY, Wefel JS, McGovern SL, Garland LL, Chen SS, Holt J, Liao Z, Brown P, Sulman E, Heymach JV, Kim ES, Stea B: Phase II trial of erlotinib plus concurrent whole-brain radiation therapy for patients with brain metastases from non-small-cell lung cancer. J Clin Oncol 2013, 31:895-902.

\section{FlOOOPrime \\ RECOMMENDED}

53. Gerber NK, Yamada Y, Rimner A, Shi W, Riely GJ, Beal K, Yu HA, Chan TA, Zhang Z, Wu A): Erlotinib versus radiation therapy for brain metastases in patients with EGFR-mutant lung adenocarcinoma. Int J Radiat Oncol Biol Phys 2014, 89:322-9.

\section{FlOOOPrime \\ RECOMMENDED}

54. Ceresoli GL, Cappuzzo F, Gregorc V, Bartolini S, Crinò L, Villa E: Gefitinib in patients with brain metastases from non-smallcell lung cancer: a prospective trial. Ann Oncol 2004, I 5:1042-7.

55. Park SJ, Kim HT, Lee DH, Kim KP, Kim S, Suh C, Lee JS: Efficacy of epidermal growth factor receptor tyrosine kinase inhibitors for brain metastasis in non-small cell lung cancer patients harboring either exon 19 or 21 mutation. Lung Cancer 2012, 77:556-60.

\section{FlOOOPrime \\ RECOMMENDED}

56. Wu Y, Zhou C, Cheng Y, Lu S, Chen G, Huang C, Huang Y, Yan H, Ren S, Liu $Y$, Yang J: Erlotinib as second-line treatment in patients with advanced non-small-cell lung cancer and asymptomatic brain metastases: a phase II study (CTONG0803). Ann Oncol 2013, 24:993-9.

57. Lin NU, Carey LA, Liu MC, Younger J, Come SE, Ewend M, Harris G], Bullitt E, Van den Abbeele, Annick D, Henson JW, Li X, Gelman R, Burstein HJ, Kasparian E, Kirsch DG, Crawford A, Hochberg F, Winer EP: Phase II trial of lapatinib for brain metastases in patients with human epidermal growth factor receptor 2-positive breast cancer. J Clin Oncol 2008, 26:1993-9.

58. Lin NU, Diéras V, Paul D, Lossignol D, Christodoulou C, Stemmler H, Roché H, Liu MC, Greil R, Ciruelos E, Loibl S, Gori S, Wardley A, Yardley D, Brufsky A, Blum JL, Rubin SD, Dharan B, Steplewski K, Zembryki D, Oliva C, Roychowdhury D, Paoletti P, Winer EP: Multicenter phase II study of lapatinib in patients with brain metastases from HER2-positive breast cancer. Clin Cancer Res 2009, I 5: | 452-9.

\section{FlOOOPrime \\ RECOMMENDED}

59. Lin NU, Eierman W, Greil R, Campone M, Kaufman B, Steplewski K, Lane SR, Zembryki D, Rubin SD, Winer EP: Randomized phase II study of lapatinib plus capecitabine or lapatinib plus topotecan for patients with HER2-positive breast cancer brain metastases. J Neurooncol 20II, 105:6|3-20.

60. Bachelot T, Romieu G, Campone M, Diéras V, Cropet C, Dalenc F, Jimenez M, Le Rhun E, Pierga J, Gonçalves A, Leheurteur M, Domont J, Gutierrez M, Curé H, Ferrero J, Labbe-Devilliers C: Lapatinib plus capecitabine in patients with previously untreated brain metastases from HER2-positive metastatic breast cancer (LANDSCAPE): a single-group phase 2 study. Lancet Oncol 2013, 14:64-7I.

\section{FlOOOPrime}

\section{RECOMMENDED}

6I. Davies H, Bignell GR, Cox C, Stephens P, Edkins S, Clegg S, Teague J, Woffendin H, Garnett MJ, Bottomley W, Davis N, Dicks E, Ewing R, Floyd Y, Gray K, Hall S, Hawes R, Hughes J, Kosmidou V, Menzies A, Mould C, Parker A, Stevens C, Watt S, Hooper S, Wilson R, Jayatilake H, Gusterson BA, Cooper C, Shipley J et al.: Mutations of the BRAF gene in human cancer. Nature 2002, 417:949-54.

\section{FlOOOPrime
RECOMMENDED}

62. Long GV, Trefzer U, Davies MA, Kefford RF, Ascierto PA, Chapman PB, Puzanov I, Hauschild A, Robert C, Algazi A, Mortier L, Tawbi H, Wilhelm T, Zimmer L, Switzky J, Swann S, Martin A, Guckert M, Goodman V, Streit M, Kirkwood JM, Schadendorf D: Dabrafenib in patients with Val600Glu or Val600Lys BRAF-mutant melanoma metastatic to the brain (BREAK-MB): a multicentre, open-label, phase 2 trial. Lancet Oncol 2012, 13:1087-95.

\section{FlOOOPrime} RECOMMENDED

63. Dummer R, Goldinger SM, Turtschi CP, Eggmann NB, Michielin $O$, Mitchell L, Veronese L, Hilfiker PR, Felderer L, Rinderknecht JD: Vemurafenib in patients with BRAF(V600) mutation-positive melanoma with symptomatic brain metastases: final results of an open-label pilot study. Eur J Cancer 20I4, 50:6II-2I.

\section{FIOOOPrime \\ RECOMMENDED}

64. Wilson $\mathrm{EH}, \mathrm{Weninger} \mathrm{W}$, Hunter $\mathrm{CA}$ : Trafficking of immune cells in the central nervous system. J Clin Invest 2010, 120:1368-79.

65. Margolin K, Ernstoff MS, Hamid O, Lawrence D, McDermott D, Puzanov I, Wolchok JD, Clark Jl, Sznol M, Logan TF, Richards J, Michener T, Balogh A, Heller KN, Hodi FS: Ipilimumab in patients with melanoma and brain metastases: an open-label, phase 2 trial. Lancet Oncol 2012, 13:459-65.

\section{FlOOOPrime
RECOMMENDED}

66. Suh JH, Stea B, Nabid A, Kresl JJ, Fortin A, Mercier J, Senzer N, Chang EL, Boyd AP, Cagnoni PJ, Shaw E: Phase III study of efaproxiral as an adjunct to whole-brain radiation therapy for brain metastases. J Clin Oncol 2006, 24:106-14.

\section{FlOOOPrime}

67. Lin NU, Lee EQ, Aoyama H, Barani IJ, Baumert BG, Brown PD, Camidge DR, Chang SM, Dancey J, Gaspar LE, Harris GJ, Hodi FS, Kalkanis SN, Lamborn KR, Linskey ME, Macdonald DR, Margolin K, Mehta MP, Schiff D, Soffietti R, Suh JH, van den Bent, Martin J, Vogelbaum MA, Wefel JS, Wen PY: Challenges relating to solid tumour brain metastases in clinical trials, part I: patient population, response, and progression. A report from the RANO group. Lancet Oncol 2013, I4:e396-406.

68. Steeg PS, Camphausen KA, Smith QR: Brain metastases as preventive and therapeutic targets. Nat Rev Cancer 20I I, I I:352-63.

69. Pivot X, Semiglazov V, Zurawski B, Allerton R, Fabi A, Ciruelos E, Parikh R, DeSilvio M, Santillana S, Swaby R: CEREBEL (EGFIII438): an open label randomized phase III study comparing the incidence of CNS metastases in patients (pts) with HER2 positive metastatic breast cancer (MBC), treated with lapatinib plus capecitabine (LC) versus trastuzumab plus capecitabine (TC) [abstract]. Presented at ESMO Congress 2012: 28 September - 01 ${ }^{\text {st }}$ October 2012; Vienna, Austria. 